\title{
Lid surgery for trachomatous trichiasis is negatively associated with visual disabilities and visual impairment in Oman
}

\author{
R.B. Khandekar, ${ }^{1}$ S.S. Al Harby ${ }^{7}$ and U.P Vora ${ }^{7}$
}

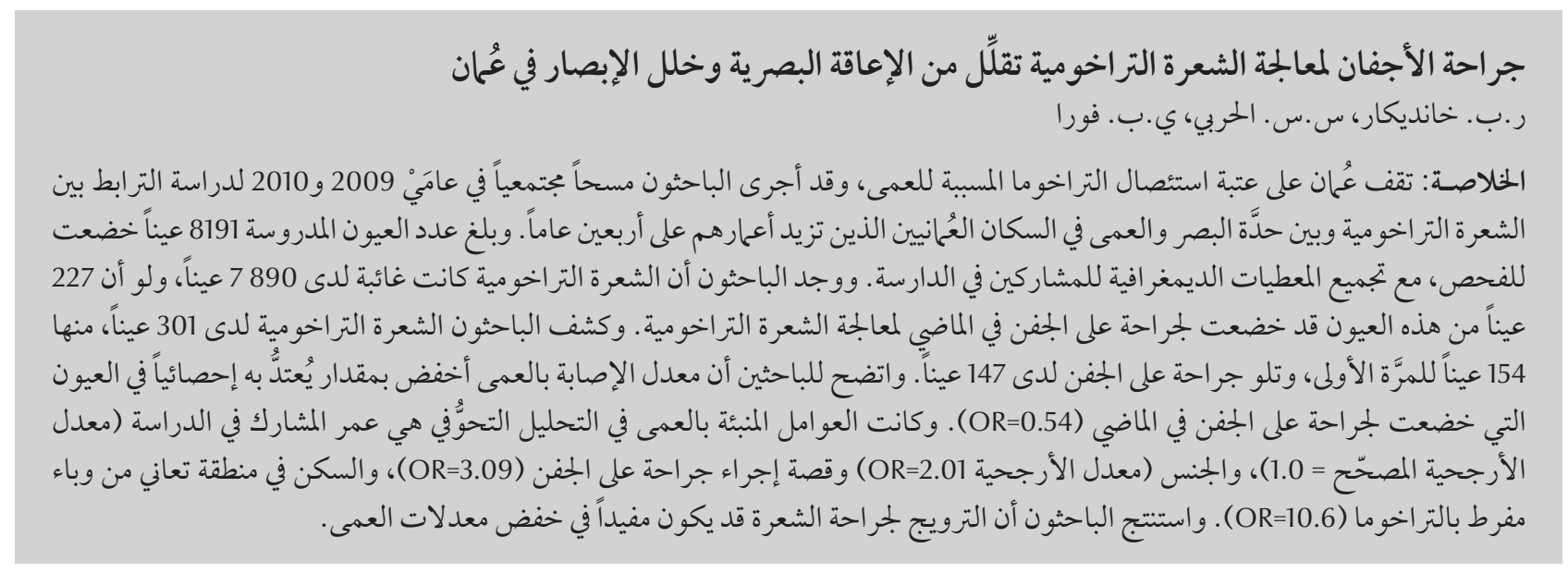

ABSTRACT Oman is at the threshold of eliminating blinding trachoma. We conducted a community-based survey in 2009-10 to study the association of trachomatous trichiasis (TT) status with visual acuity and blindness among the Omani population aged 40+ years. A total of 8191 eyes were examined and participants' demographic data were collected. TT was absent in 7890 eyes but 227 of these eyes had had lid surgery for $T T$ in the past. $\Pi T$ was detected in 301 eyes, for the first time in 154 eyes and following lid surgery in 147 eyes. The rate of blindness was significantly lower in eyes that had undergone lid surgery in the past $(O R=0.54)$. In regression analysis the predictors of blindness were participant's age (adjusted $O R=1.01)$, sex $(\mathrm{aOR}=2.01)$, history of lid surgery $(\mathrm{aOR}=$ $3.09)$ and residence in a hyperendemic trachoma area $(\mathrm{aOR}=10.6)$. Promotion of $T \mathrm{~T}$ surgery might be beneficial in reducing blindness.

Association négative de la chirurgie des paupières pour le trichiasis trachomateux aux déficiences visuelles et à la malvoyance à Oman

RÉSUMÉ Oman est sur le point d'éliminer le trachome cécitant. Nous avons mené une enquête dans la communauté entre 2009 et 2010 pour étudier l'association du trichiasis trachomateux avec l'acuité visuelle et la cécité dans la population d'Omanais de plus de 40 ans. Au total, 8191 yeux ont été examinés et les données démographiques des participants ont été recueillies. La recherche du trichiasis trachomateux s'est révélée négative pour 7890 yeux mais 227 d'entre eux avaient des antécédents de chirurgie des paupières. La maladie a été détectée dans 301 yeux, pour la première fois dans 154 yeux et après une chirurgie des paupières dans 147 yeux. Le taux de cécité était significativement inférieur pour les yeux ayant des antécédents de chirurgie des paupières $(O R=0,54)$. À l'analyse de régression, les facteurs prédictifs de la cécité étaient l'âge du patient (OR ajusté $=1,01)$, le sexe $(O R a=2,01)$, les antécédents de chirurgie des paupières $(O R a=3,09)$ et le lieu de résidence dans une zone où le trachome est hyperendémique $(\mathrm{ORa}=10,6)$. La promotion de la chirurgie du trichiasis trachomateux pourrait contribuer à limiter les cas de cécité. 


\section{Introduction}

Trachoma is a priority health problem, and the World Health Organization (WHO) has expressed its commitment to the elimination of blinding trachoma by the year 2020 [1]. In a concerted approach, named the Global Alliance for Elimination of Blinding Trachoma, the representatives of Member States adopted the guidelines to reach this objective and stipulated indicators to review the progress [2].

The surgery component of the SAFE strategy [S (surgery), A (antibiotic), F (facial cleanliness), E (environmental improvement)] is an indirect indicator of blindness due to trachoma. By linking the presence or absence of trachomatous trichiasis (TT) to visual status we can assess the association of a particular strategy-namely lid surgery for $\mathrm{T}$ - with the reduction in blindness.

Previous researchers have associated visual acuity and blindness status to $\Pi \Gamma$ in countries with high trachoma prevalence [3-6]. It would be interesting to study this association in a country that is at the threshold of eliminating blinding trachoma [7]. We therefore conducted a communitybased survey in 2009-10 to study the association of trachomatous trichiasis (TT) status with visual acuity and blindness among the Omani population aged $40+$ years.

\section{Methods}

This paper reports a review of the data collected through a cross-sectional study in the community. The National Blinding Trachoma Certification Committee received approval to undertake this survey from the research and ethics committee of the Ministry of Health, Oman. The study was conducted in trachoma endemic areas during the last 2 months of 2009 and the first 2 months of 2010 .

\section{Sample}

During the last survey in 1996, 22 wilayat of 3 governorates of Oman were found to be trachoma endemic. The study population was Omani people aged $40+$ years in these endemic areas who were identified from on the catchment area population of primary health (PHC) centres. By using a random selection method 2 PHCs of each wilaya were selected and 1 randomly selected village for each selected PHC was visited for the survey. We identified a central mosque as the starting point. The first house in the eastwards direction was selected as the starting house and all Omani residents aged $40+$ years in these houses were enrolled. The visits were continued until the required 100 persons (200 eyes) from the village were obtained. Further details are given in our earlier publication [8].

\section{Data collection}

The data was collected on a pre-tested form. The field investigators were qualified optometrists with experience of trachoma screening. They used an ophthalmic loupe (Keeler UK 2.5X) to detect $\Pi$. The methods of assessing visual acuity and $\mathrm{TT}$ are given in more detail in our earlier publication [8]. To minimize misclassification of senile entropion cases as $\Pi$, we excluded eyes with lower lid trichiasis alone and those without severe trachomatous scarring.

Distant visual acuity was assessed using a Snellen distant vision chart at $6 \mathrm{~m}$ distance from the participant. If a person was using spectacles for viewing distant objects, his/her vision was tested with the spectacles. Distant visual acuity was further divided into moderate visual impairment (vision 6/18-6/60) and severe visual impairment (vision < $6 / 60-3 / 60$ ). If vision was $<3 / 60$ the vision was tested again using a pinhole. Blindness was defined as the best corrected visual acuity of $<3 / 60$. We used a pinhole to ensure the best corrected vision in eyes with vision $<3 / 60$. Due to poor cooperation of a few participants, data on visual acuity of their eyes was missing but their blindness status (based on recognizing single optotype 'E' at $3 \mathrm{~m}$ distance) using a pinhole was documented.

History of lid surgery for $\mathrm{T}$ in the past was inquired about from the participant and relatives. Lid surgery for senile entropion was not included. Information about other ocular surgery (e.g. cataract, glaucoma, pterygium, keratoplasty, retinal surgery, laser surgery for diabetes, surgery for correcting refractive error and eye removal) was compiled through both interview and eye examination. History of surgery was confirmed from the patient's health records.

Demographic information (age, sex and the area of residence) were also collected. If the residence was in Dhakhiliya, North Sharqiya or South Batinah regions of Oman, the area was defined as a trachoma hyperendemic area. If the area of residence was in North Batinah, South Sharqiya, Dhahira or Buraimi regions, the person was considered to be from a mesoendemic area of trachoma.

The eyes were grouped into 4 groups: $T$ absent at the time of examination and no history of lid surgery for $\mathrm{T}$ (never had $\mathrm{T}$ ), $\mathrm{T}$ absent but evidence/history of lid surgery for $\mathrm{TT}$ (successfully managed cases); TT present during eye examination but no history of lid surgery (new cases); and $\mathrm{TT}$ present and evidence/history of lid surgery for $\mathrm{TT}$ (recurrent cases).

\section{Data analysis}

Epi-data, version 3.1, software was used for data entry [9]. The spreadsheet was converted using SPSS, version 11.5. We used parametric univariate analysis to calculate frequencies and percentage proportions and binominal logistic regression analysis to identify predictors and to review the interaction of different variables associated to the blindness. 
The adjusted odds ratios (OR), 95\% confidence interval (CI) and $P$-values were calculated. Variables known to influence the presence of $\mathrm{TT}$ were included in the regression model and the stepwise method was used to study the interaction.

\section{Results}

\section{Trachomatous trichiasis status}

We enrolled 8616 eyes of 4308 people in this study; data were omitted from analysis for people absent during the survey (378 eyes) and those refusing to participate (47 eyes). We therefore examined 8191 (95.1\%) eyes. The TT status of eyes by the demographic profile of participants is shown in Table 1. TT was not present at the time of examination in 7890 eyes and, of these, evidence of past lid surgery was noted for 227 eyes. TT was detected in 301 eyes at examination, of which 147 eyes had evidence of lid surgery in the past to treat $\Pi$ (recurrent cases), while in 154 eyes $T T$ was noted for the first time (new cases).

\section{Trachomatous trichiasis status by blindness status}

The $T$ status and blindness status of eyes was analysed (Table 2). The rate of blindness was not significantly different between the surgery positive and negative groups when $T$ was absent (OR $=1.64$; $95 \%$ CI: $0.89-3.00)$ or when TT was present $(\mathrm{OR}=2.19$; $95 \% \mathrm{CI}$ : 0.74-6.45).

\section{Blindness status by history of lid surgery}

We analysed the blindness rate in relation to history of lid surgery by combing groups and comparing eyes that had never had $T \Gamma$ surgery with eyes that had had TT surgery (Table 3). Eyes that had undergone lid surgery had a significantly lower rate of blindness compared with eyes that had not undergone lid surgery in the past $(\mathrm{OR}=0.54 ; 95 \%$ CI: 0.32-0.89). However, comparing lid surgery for $T \Gamma$ in the past and blindness between males and females showed that sex was a confounding factor in this association $(\mathrm{OR}=0.39$; $95 \% \mathrm{CI}$ : $0.12-0.99$ for males and $\mathrm{OR}=0.76 ; 95 \%$ CI: $0.40-1.33$ for females) (Table 3 ).
We also reviewed the influence of residence in trachoma-endemic areas on the association of lid surgery for $\mathrm{TT}$ and blindness (Table 3). The association of lid surgery for $T T$ in the past and blindness was significant in the eyes of people residing in hyperendemic $(\mathrm{OR}=1.03$; 95\% CI: 0.6-1.8) and mesoendemic areas $(\mathrm{OR}=0.57 ; 95 \% \mathrm{CI}$ : $0.6-1.8)$.

\section{Associations between variables}

Regression analysis enabled us to study the interaction of different variables with blindness status. Presence of blindness in an eye could be predicted by knowing the person's age (adjusted $\mathrm{OR}=1.01 ; 95 \% \mathrm{CI}: 1.00-1.02)$, sex (adjusted OR $=2.01$; 95\% CI: $1.68-$ 2.41), history of lid surgery (adjusted $\mathrm{OR}=3.09 ; 95 \% \mathrm{CI}: 2.32-4.11$ and trachoma endemicity of residential area (adjusted OR $=10.6$; 95\% CI: 8.85-12.7) (Table 4).

Visual acuity (with correction by spectacles for distance) was studied in relation to $T \Gamma$ status (Figure 1). Excellent quality of vision $(6 / 6-6 / 18)$

\begin{tabular}{|c|c|c|c|c|c|c|c|c|}
\hline \multicolumn{9}{|c|}{$\begin{array}{l}\text { Table } 1 \text { Demographic profile of pa } \\
\text { lid surgery for TT ( } n=8191 \text { eyes) }\end{array}$} \\
\hline \multirow[t]{3}{*}{ Variable } & \multicolumn{4}{|c|}{ TT absent $(n=7890)$} & \multicolumn{4}{|c|}{ TT present $(n=301)$} \\
\hline & \multicolumn{2}{|c|}{$\begin{array}{l}\text { Surgery history -ve } \\
\text { (never had TT) }\end{array}$} & \multicolumn{2}{|c|}{$\begin{array}{l}\text { Surgery history +ve } \\
\text { (successfully managed) }\end{array}$} & \multicolumn{2}{|c|}{$\begin{array}{l}\text { Surgery history -ve } \\
\text { (new cases) }\end{array}$} & \multicolumn{2}{|c|}{$\begin{array}{l}\text { Surgery history +ve } \\
\text { (recurrence) }\end{array}$} \\
\hline & No. & $\%$ & No. & $\%$ & No. & $\%$ & No. & $\%$ \\
\hline \multicolumn{9}{|l|}{ Sex } \\
\hline Male & 2925 & 38.2 & 52 & 22.9 & 45 & 29.2 & 30 & 20.4 \\
\hline Female & 4738 & 61.8 & 175 & 77.1 & 109 & 70.8 & 117 & 79.6 \\
\hline \multicolumn{9}{|l|}{ Age (years) } \\
\hline $40-49$ & 3477 & 45.4 & 17 & 7.5 & 11 & 7.1 & 8 & 5.4 \\
\hline $50-59$ & 1699 & 22.2 & 65 & 28.6 & 33 & 21.4 & 27 & 18.4 \\
\hline $60-69$ & 1433 & 18.7 & 74 & 32.6 & 67 & 43.5 & 57 & 38.8 \\
\hline $70-79$ & 707 & 9.2 & 36 & 15.9 & 26 & 16.9 & 36 & 24.5 \\
\hline $80+$ & 335 & 4.4 & 35 & 15.4 & 17 & 11.0 & 19 & 12.9 \\
\hline \multicolumn{9}{|l|}{ Region $^{a}$} \\
\hline Hyperendemic & 6526 & 85.2 & 219 & 96.5 & 135 & 59.5 & 145 & 98.6 \\
\hline Mesoendemic & 1137 & 14.8 & 8 & 3.5 & 19 & 8.4 & 2 & 1.4 \\
\hline Total & 7074 & 100.0 & 216 & 100.0 & 143 & 100.0 & 142 & 100.0 \\
\hline
\end{tabular}




\begin{tabular}{|c|c|c|c|c|c|}
\hline \multirow[t]{2}{*}{ Variable } & \multicolumn{2}{|c|}{$\begin{array}{c}\text { Blind } \\
\text { (vision }<3 / 60 \text { ) }\end{array}$} & \multicolumn{2}{|c|}{$\begin{array}{c}\text { Not blind } \\
\text { (vision } \geq 3 / 60 \text { ) }\end{array}$} & \multirow[t]{2}{*}{ OR $(95 \% \mathrm{Cl})$} \\
\hline & No. & $\%$ & No. & $\%$ & \\
\hline \multicolumn{6}{|l|}{ TTabsent } \\
\hline Surgery history -ve (never had TT) & 589 & 7.7 & 7074 & 92.3 & \multirow{3}{*}{$1.64(0.89-3.00)$} \\
\hline $\begin{array}{l}\text { Surgery history +ve (successfully } \\
\text { managed) }\end{array}$ & 11 & 4.8 & 216 & 95.2 & \\
\hline Subtotala & 600 & 7.6 & 7290 & 92.4 & \\
\hline \multicolumn{6}{|l|}{ Tाpresent } \\
\hline Surgery history -ve (new cases) & 11 & 7.1 & 143 & 92.9 & \multirow[t]{4}{*}{$2.19(0.74-6.45)$} \\
\hline Surgery history +ve (recurrence) & 5 & 3.4 & 142 & 96.6 & \\
\hline Subtotal $^{\mathrm{a}}$ & 16 & 5.3 & 285 & 94.7 & \\
\hline Eyes examined for $\Pi T$ & 616 & 7.5 & 7575 & 92.5 & \\
\hline
\end{tabular}

Data presented are numbers and \% of eyes examined.

${ }^{a}$ Odds of having blindness among eyes with TT now compared to eyes without TT at present: $O R=1.47,95 \%$ CI: $0.88-2.44$.

$O R=$ odds ratio; $C l=$ confidence interval.

was found in a higher proportion of vision $(<3 / 60)$ was noted in a higher eyes that had never had TT com- proportion of eyes with recurrence pared with new cases. Poor quality of of TT.

\section{Other surgeries}

Among the group with no $\mathrm{TT}$ and no history of TT surgery, $111(1.6 \%)$ eyes

\begin{tabular}{|c|c|c|c|c|c|}
\hline \multirow[t]{2}{*}{ Variable } & \multicolumn{2}{|c|}{$\begin{array}{c}\text { Blind } \\
\text { (vision }<3 / 60 \text { ) }\end{array}$} & \multicolumn{2}{|c|}{$\begin{array}{c}\text { Not blind } \\
\text { (vision } \geq 3 / 60 \text { ) }\end{array}$} & \multirow[t]{2}{*}{ OR $(95 \% \mathrm{Cl})$} \\
\hline & No. & $\%$ & No. & $\%$ & \\
\hline \multicolumn{6}{|l|}{ Total group } \\
\hline Surgery history -ve & 600 & 97.4 & 7217 & 95.3 & \multirow[t]{3}{*}{$0.54(0.32-0.89)$} \\
\hline Surgery history +ve & 16 & 2.6 & 358 & 4.7 & \\
\hline Total & 616 & 100.0 & 7575 & 100.0 & \\
\hline \multicolumn{6}{|l|}{ Males } \\
\hline Surgery history -ve & 342 & 98.8 & 2628 & 97.1 & \multirow[t]{3}{*}{$0.39(0.12-0.99)$} \\
\hline Surgery history +ve & 4 & 1.2 & 78 & 2.9 & \\
\hline Subtotal & 346 & 100.0 & 2706 & 100.0 & \\
\hline \multicolumn{6}{|l|}{ Females } \\
\hline Surgery history -ve & 258 & 95.6 & 4589 & 94.2 & \multirow[t]{3}{*}{$0.76(0.40-1.33)$} \\
\hline Surgery history +ve & 12 & 4.4 & 280 & 5.8 & \\
\hline Subtotal & 270 & 100.0 & 4869 & 100.0 & \\
\hline \multicolumn{6}{|l|}{ Hyperendemic area } \\
\hline Surgery history -ve & 248 & 93.9 & 6413 & 94.8 & \multirow[t]{3}{*}{$1.03(0.60-1.80)$} \\
\hline Surgery history +ve & 14 & 5.3 & 350 & 5.2 & \\
\hline Subtotal & 364 & 100.0 & 6661 & 100.0 & \\
\hline \multicolumn{6}{|l|}{ Mesoendemic area } \\
\hline Surgery history -ve & 352 & 99.4 & 804 & 99.0 & \multirow[t]{3}{*}{$0.57(0.12-2.70)$} \\
\hline Surgery history +ve & 2 & 0.6 & 8 & 1.0 & \\
\hline Subtotal & 354 & 100.0 & 812 & 100.0 & \\
\hline
\end{tabular}

Data presented are numbers and \% of eyes examined. $\mathrm{OR}=$ odds ratio; $\mathrm{Cl}=$ confidence interval. 


\begin{tabular}{lcc}
\hline $\begin{array}{l}\text { Table } 4 \text { Regression analysis of trachomatous trichiasis (TT) and blindness status of } \\
\text { participants' eyes }\end{array}$ & Adjusted OR (95\% Cl) & P-value \\
\hline Variable & $1.01(1.00-1.02)$ & $<0.001$ \\
Age & $2.01(1.68-2.41)$ & $<0.001$ \\
Sex & 1 & \\
$\quad \begin{array}{l}\text { Male } \\
\text { Female }\end{array}$ & $10.6(8.85-12.7)$ & \\
Study area & 1 & 0.001 \\
Hyperendemic & & \\
Mesoendemic & $0.92(0.52-1.57)$ & \\
Type of $\pi$ & 1 & $<0.7$ \\
TT recurrence & & \\
No TT recurrence & $3.09(2.32-4.11)$ & \\
History oflid surgery & 1 & \\
Yes & & \\
No &
\end{tabular}

Intercept $=-7.174$.

$O R=$ odds ratio $; C l=$ confidence interval.

of persons with a mean age of 52.9 years had undergone cataract surgery in the past. Aphakia or pseudophakia was noted in $216(18.5 \%)$ eyes of those who had been successfully managed for $\Pi \pi$ (mean age 63.3 years). In the group of new cases of $T \Gamma, 11$ out of $143(7.7 \%)$ eyes of persons (mean age 63.1 years) were operated for cataract. Finally, in the recurrent cases, 31 (21.8\%) of 142 eyes of persons with $\pi T$ recurrence (mean age
64.9 years) had undergone cataract surgery.

\section{Discussion}

In the current study in Oman the risk of severe visual impairment in eyes that had not undergone $T \mathrm{~T}$ surgery was significantly higher than eyes operated for $\Pi T$ in the past. However, there was no statistically significant difference in the rate of blindness and severe visual impairment among those with $\Pi \mathrm{T}$ and without TT. Woreta et al. in Ethiopia noted that bilamellar tarsal rotation surgery was associated with improvement in visual acuity compared with no surgery $(\mathrm{OR}=1.68)$ [3]. In Vietnam, ophthalmologists used a modified $\mathrm{Cu}$ neod Nataf procedure for lid surgery to manage $\Pi T$ cases and noted that the poor visual acuity was associated with recurrence at 1 year follow-up [10]. A controlled trial in Oman in the late 1980s by Reacher et al. suggested that surgery for major trichiasis produced a significant improvement in visual acuity in operated versus non-operated fellow eyes [11]. In these countries, blindness was mainly due to infectious and age-related blinding eye diseases, and local eye care facilities were limited [12]. Hence the observed decline in visual disabilities following lid surgery could be attributed to proactive $\mathrm{TT}$ intervention campaigns. In contrast, the present study in Oman was carried out 10 years after implementing VISION 2020 strategies and at a time when high-quality eye care services for refractive error, cataract, glaucoma and diabetic retinopathy were accessible and affordable to all.

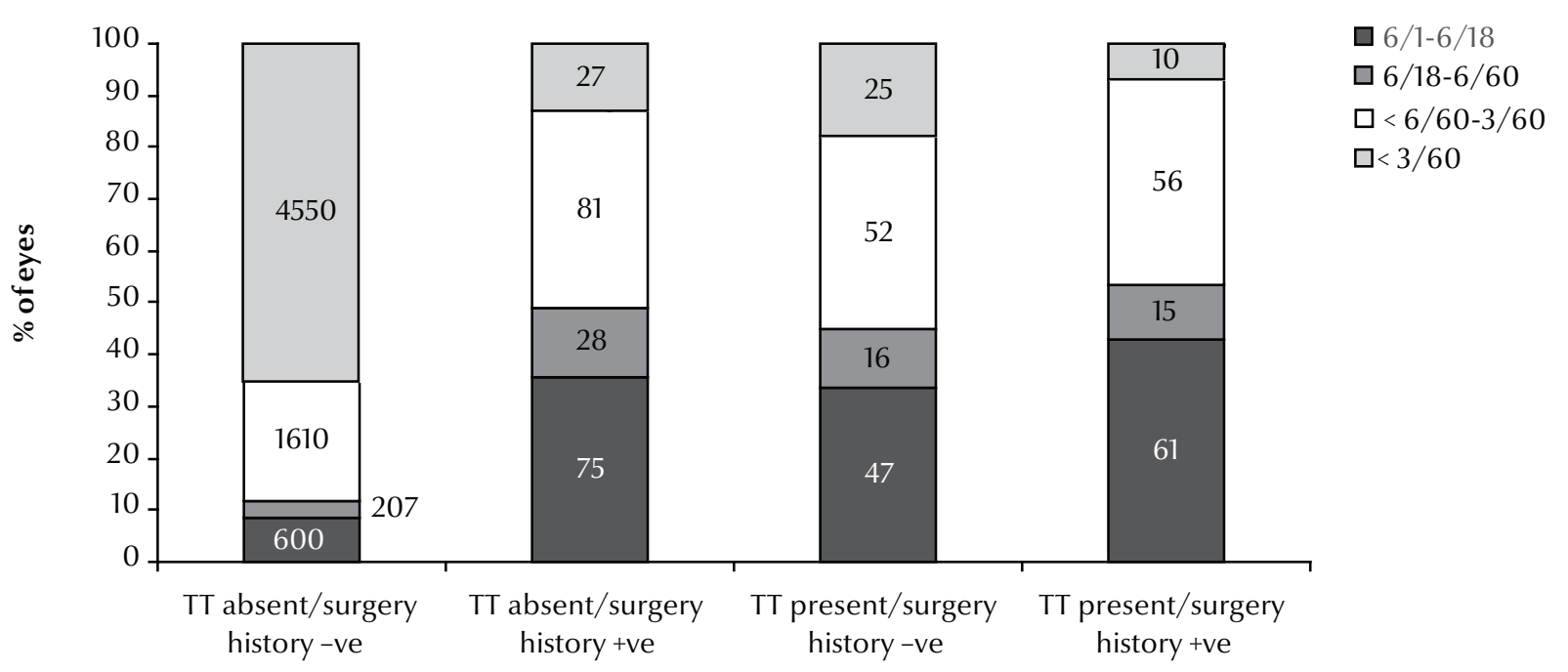

Figure 1 Visual acuity (with correction by spectacles for distance), by presence of trachomatous trichiasis (TT) in eyes at examination and history of lid surgery for $\mathrm{TT}$ (data are number of eyes) 
We noted that female sex was associated with visual impairment and lid surgery for $\Pi \mathrm{T}$ in our study. A previous study in Oman also found that females had a higher risk of trichiasis, which was attributed to barriers for trichiasis surgery [13]. In Sudan too women have been reported to live longer and suffer a longer duration of disabling trichiasis and visual disabilities compared with males [14]. Despite the decline in blinding trachoma in a country such as Oman, the gender gap might still be important and approaches need to be modified to bridge the gender gap.

Age was a significant confounder for the association of $\mathrm{TT}$ and visual impairment in our study. A similar observation was noted in rural Myanmar, where the risk of trachoma increased by $5.3 \%$ for each 1 year increase in age. The rate of visual disabilities also increased with age [15]. The prevalence of age-related blinding eye diseases such as cataract, glaucoma and age-related macular degeneration were higher in older age groups. This could also be the reason for higher rates of visual impairment in older age groups.

The risk of blindness among eyes with trichiasis was higher among residents of mesoendemic areas than hyperendemic areas in our study. Frequent screening campaigns and management of other blinding eye diseases among the target population of hyperendemic areas could explain this variation. In other studies too the residential area of participants has been documented to influence both blindness and $T \pi$. In desert areas of Australia, for example, the risk of $\mathrm{T}$ and blindness was higher compared with coastal areas $[6,16]$.

The rates of blindness and severe visual impairment were higher among individuals with $\mathrm{TT}$ and recurrence of $\Pi T$ compared with those without $\Pi \mathrm{T}$ in our study. A linear correlation of visual status and $\Pi \mathrm{T}$ status was also noted in Ethiopia and southern Sudan [4].

The outcomes of keratoplasty, which is the main mode of management for trachomatous corneal opacity, are not very encouraging and therefore the prevention of trachomatous corneal opacity is very important [17]. Thus, lid surgery to prevent the development of advanced corneal opacities and dry eye due to trachoma is recommended in countries with a high prevalence of blinding trachoma.

Corneal blindness due to the sequelae of trachoma is still the main reason for visual disability among the adult population in many countries where active trachoma is no longer a public health problem [18]. The goal of the GET2020 initiative of eliminating avoidable blindness due to trachoma could be achieved in these countries only if surgery for treating $T \Gamma$ were able to reduce corneal blindness. By implementing the SAFE strategy for trachoma control, it has been shown that rates of active trachoma and blinding trachoma can be reduced [2]. But indicators devised to monitor the progress of a country do not include the indicator which points to the decline in corneal blindness and visual disabilities due to trachoma. Hence indirect evidence to suggest that $T$ intervention is associated with fewer visual disabilities will be a useful tool to promote $T \Gamma$ surgery.

In the past, we studied visual acuity and lid surgery as cross-sectional data. This was a limitation in interpreting the association of lid surgery and visual impairment. In a cohort study in India, Monga et al. demonstrated that lenticular and retinal causes rather than entropion were the main responsible causes of blindness [19]. In the present study, the age-related blinding eye diseases such as cataract were managed in a higher proportion in the group of eyes having $T T$ than in the group of eyes without TT. Hence blindness and visual impairment in persons with and without TT might not be affected by different rates of cataract-related blindness.

Senile entropion/trichiasis is known to have fewer corneal complications compared with Tा [20]. Thus, misclassification of trichiasis/entropion of a senile nature and $\mathrm{TT}$ could influence the association of visual impairment and TT intervention. The exclusion criteria used in the present study enabled us to minimize the effect of this bias and its impact on the results. In a previous survey in Oman more than half of the eyes of persons aged $40+$ years and residing in hyperendemic areas of trachoma had severe trachomatous scarring [21].

Persons undergoing lid surgery for TT had a lower rate of visual disability compared with those without TT. Perhaps frequent attention by eye care personnel might have brought the attention of patients and their relatives to the blinding eye disease and its management. It is also be possible that by undergoing lid surgery, an eye with $T T$ could also show improvement in visual acuity. The eyes that had a recurrence of $T T$ had a higher risk of visual disabilities compared with eyes without $\Pi$. This is natural as frequent injury to the cornea by eyelashes could result in severe corneal opacity and secondary infection leading to blindness. Further longitudinal studies are recommended to confirm the observed association in our study.

In conclusion, $\mathrm{T}$ surgery seems to have a beneficial effect in reducing visual disabilities. Countries and organizations should promote $\Pi \mathrm{T}$ surgery and focus more on reducing $T T$ recurrence.

\section{Acknowledgements}

We thank the National Eye Health Care Committee and regional health administrators of Oman for their support in this survey. The community support group volunteers assisted the investigators especially for increasing the response rate. The field staff visited the villages and worked beyond the call of duty in order to conclude the survey in time. We sincerely appreciate their efforts. The residents of the selected villages were very cooperative in this health survey. We thank all of them.

The article was presented at a trachoma scientist's meeting at the World Health Organization on 15 April 2011. 


\section{References}

1. Mariotti SP, Pararajasegaram R, Resnikoff S. Trachoma: looking forward to Global Elimination of Trachoma by 2020 (GET 2020). American Journal of Tropical Medicine and Hygiene, 2003, 69:33-35.

2. WHA51.11 1998. Global elimination of blinding trachoma. World Health Organization [online] (http://www.who.int/pbd/ publications/wha_eb/wha51_11/en/index.html, accessed 23 September 2012).

3. Woreta TA et al. Effect of trichiasis surgery on visual acuity outcomes in Ethiopia. Archives of Ophthalmology, 2009, 127:1505-1510.

4. Ngondi J et al. The epidemiology of low vision and blindness associated with trichiasis in southern Sudan. BMC Ophthalmology, 2007, 7:12.

5. Evans TG, Ranson MK. The global burden of trachomatous visual impairment: II. Assessing burden. International Ophthalmology, 1995-1996, 19:271-280.

6. Wright HR, Keeffe JE, Taylor HR. Trachoma, cataracts and uncorrected refractive error are still important contributors to visual morbidity in two remote indigenous communities of the Northern Territory, Australia. Clinical and Experimental Ophthalmology, 2009, 37:550-557.

7. Khandekar R. Trachoma in Middle Eastern countries. Middle East African Journal of Ophthalmology, 2007, 14:1-2.

8. Khandekar R et al. Oman's progress towards reaching "ultia mate intervention goals" for the surgery "S" component of SAFE strategy for the elimination of blinding trachoma in 2008. Ophthalmic Epidemiology, 2010, 17(6):360-365.

9. Lauritsen JM, ed. EpiData data entry, data management and basic statistical analysis system. Odense, Denmark, EpiData Association, 2008.

10. Thanh $\Pi \mathrm{T}$ et al. One year recurrence of trachomatous trichiasis in routinely operated Cuenod Nataf procedure cases in Vietnam. British Journal of Ophthalmology, 2004, 88:1114-1118.
11. Reacher $\mathrm{MH}$ et al. A controlled trial of surgery for trachomatous trichiasis of the upper lid. Archives of Ophthalmology, 1992, 110:667-674.

12. Melese $\mathrm{M}$ et al. Low vision and blindness in adults in Gurage zone, central Ethiopia. British Journal of Ophthalmology, 2003, 87:677-680.

13. Khandekar R, Mohammed AJ. Gender inequality in vision loss and eye diseases: evidence from the Sultanate of Oman. Indian Journal of Ophthalmology, 2009, 57:443-449.

14. Ngondi JM et al. What will happen if we do nothing to control trachoma: health expectancies for blinding trachoma in southern Sudan. PLoS Neglected Tropical Diseases, 2009, 3:396.

15. Durkin SR et al. Prevalence of trachoma-related trichiasis and corneal opacity in rural Myanmar: the Meiktila Eye Study. Ophthalmology, 2007, 114:7-11.

16. Landers J, Henderson T, Craig J. The prevalence and causes of visual impairment in indigenous Australians within central Australia: the Central Australian Ocular Health Study. British Journal of Ophthalmology, 2010, 94:1140-1144.

17. Mohan M, Panda A, Kumar TS. Results of penetrating keratoe plasty in vascularized corneas. Annals of Ophthalmology, 1990, 22:235-238.

18. Khandekar R, Mohammed AJ, Raisi AA. Prevalence and causes of blindness \& low vision; before and five years after 'VISION 2020 ' initiatives in Oman: a review. Ophthalmic Epidemiology, 2007, 14:9-15.

19. Monga P, Gupta VP, Dhaliwal U. Clinical evaluation of changes in cornea and tear film after surgery for trachomatous upper lid entropion. Eye, 2008, 22:912-917.

20. Boboridis K, Bunce C. Interventions for involutional lower lid entropion. Cochrane Database of Systematic Reviews, 2002, (1):CD002221.

21. Trachoma in blindness survey report (Oman eye study, 1996-97). Muscat, Oman, Ministry of Health, 1997:28-37. 